\title{
Microwave-assisted synthesis of high-loading, highly dispersed Pt/carbon aerogel catalyst for direct methanol fuel cell
}

\author{
ZHIJUN GUO, HONG ZHU ${ }^{\dagger, *}$, XINWEI ZHANG, FANGHUI WANG, YUBAO GUO \\ and YONGSHENG WEI \\ Department of Chemistry, School of Science, Beijing Jiaotong University, Beijing 100044, China \\ ${ }^{\dagger}$ Institute of Modern Catalyst, State Key Laboratory of Chemical Resource Engineering, School of Science, \\ Beijing University of Chemical Technology, Beijing 100029, China
}

MS received 26 July 2010; revised 14 September 2010

\begin{abstract}
A Pt supported on carbon aerogel catalyst has been synthesized by the microwave-assisted polyol process. The Pt supported on carbon aerogel catalyst was characterized by high resolution transmission electron microscopy and X-ray diffraction. The results show a uniform dispersion of spherical Pt nanoparticles 2.5-3.0 nm in diameter. Cyclic voltammetry and chronoamperometry were used to evaluate the electrocatalytic activity of the $\mathrm{Pt} /$ carbon aerogel catalyst for methanol oxidation at room temperature. The Pt/carbon aerogel catalyst shows higher electrochemical catalytic activity and stability for methanol oxidation than a commercial Pt/C catalyst of the same Pt loading.
\end{abstract}

Keywords. Direct methanol fuel cell; carbon aerogel; Pt; microwave-assisted polyol process; electrocatalyst; electrocatalytic activity.

\section{Introduction}

Polymer electrolyte fuel cells, particularly direct methanol fuel cells (DMFCs), are recognized to be a promising electrochemical device. In the last few decades, tremendous effort has been made to develop catalysts for DMFCs (Wasmus and Kuver 1999; Bai et al 2006). Despite many efforts and improvements, the commercialization of DMFC is still hindered by several factors, such as low electrocatalytic activity of catalysts for methanol oxidation, high costs of noble metal catalysts, and susceptibility of the catalysts for methanol oxidation reaction. One possibility to enhance the electrocatalytic activity of catalysts and increase the utilization of noble metal catalysts is to increase the surface area of the noble metal by dispersing it on an appropriate support. The importance of the relationship between microstructure and electrocatalytic performance is well recognized. In the past 20 years, several carbon materials such as carbon nanotube, carbon nanofiber, and tungsten carbide were studied as catalyst supports. Recently carbon aerogel (CA) has attracted attention as a new support material for electrocatalysts for fuel cells. Carbon aerogel is a new kind of carbon material (Pekala 1989; Saliger et al 1998; Maldonado-Hodar et al 1999; Liang et al 2000; Wu et al 2004). Carbon aerogel possesses high electrical conductivity, high surface area, controllable mesopores, and sharp pore size distribution. The electrocatalytic activity of catalysts is closely related to their

*Author for correspondence (zhuho128@126.com) preparation method. In recent years, the microwave-assisted heating method has received great attention as a promising method for the preparation of monodispersed nanoparticles. The microwave-assisted heating method is simple, fast, and energy efficient (Chen et al 2002; Liu et al 2004; Chen et al 2004; Tompsett et al 2006; Zhu and Zhu 2006; Ma et al 2007).

In this study, a simple microwave-assisted polyol process for preparing high-loading, highly dispersed Pt nanoparticles supported on carbon aerogel is reported. The physical and electrochemical properties of the prepared $\mathrm{Pt} / \mathrm{carbon}$ aerogel (Pt/CA) catalyst were compared with those of the commercial Pt/C catalyst JM (Johnson Matthey).

\section{Experimental}

\subsection{Preparation}

An organic aerogel was prepared by the sol-gel process from resorcinol and formaldehyde mixtures dissolved in water with sodium carbonate as catalyst. The carbon aerogel was obtained from the carbonization of the dried organic aerogel in a quartz tube furnace at $1050^{\circ}$ for 4 hours under a nitrogen atmosphere. $\mathrm{Pt} / \mathrm{CA}$ catalysts were prepared from the platinum precursor $\mathrm{H}_{2} \mathrm{PtCl}_{6} \cdot 6 \mathrm{H}_{2} \mathrm{O}$. In a $100 \mathrm{~mL}$ beaker, an ethylene glycol solution of $\mathrm{H}_{2} \mathrm{PtCl}_{6}(10.8 \mathrm{~mL}, 19.3 \mathrm{mM} / \mathrm{L})$ was mixed with $25 \mathrm{~mL}$ of ethylene glycol, followed by 30 minutes of ultrasonic agitation. Then $0.4 \mathrm{~mL}$ of $0.4 \mathrm{M}$ 
$\mathrm{KOH}$ solution was added dropwise. Carbon aerogel powder $(0.06 \mathrm{~g})$ was uniformly dispersed in the final solution by ultrasonic agitation. The beaker was placed at the centre of a microwave oven (Galanz, $2450 \mathrm{MHz}, 800 \mathrm{~W}$ ) and heated for $180 \mathrm{~s}$ (in 6 cycles of $20 \mathrm{~s}$ on with $10 \mathrm{~s}$ off). The resulting suspension was filtered, and the residue was washed with deionized water and then dried in a vacuum oven at $80^{\circ} \mathrm{C}$ for 12 hours. The dried residue $(0 \cdot 01 \mathrm{~g})$ was mixed with ethanol $(4 \mathrm{~mL})$ and $2.5 \mathrm{wt} \%$ Nafion (Aldrich) $(0.1 \mathrm{~mL})$ with ultrasonic stirring to form a homogeneous ink. The working electrode was prepared by dropping $10 \mu \mathrm{L}$ of the ink onto a commercial glassy carbon (GC) disk electrode by a microsyringe and drying at room temperature.

\subsection{Characterization}

X-ray diffraction (XRD) patterns of the Pt/CA catalyst and $\mathrm{Pt} / \mathrm{C}$ catalyst (JM) were recorded with a powder X-ray diffractometer (Rigaku, D/MAX-RB) using Cu Kà radiation with a Ni filter. The tube current was $40 \mathrm{~mA}$ with a tube voltage of $40 \mathrm{kV}$. The angle was extended from 15 to $85^{\circ}$ at a step size of $0.02^{\circ}$. The morphology of the catalyst was characterized by high resolution transmission electron microscopy (HRTEM, JEM-3010). Electrochemical measurements were carried out in a $250 \mathrm{~mL}$ three-electrode cell at $25^{\circ} \mathrm{C}$ with the use of an electrochemistry workstation (CHI 760B). A $\mathrm{GC}$ electrode (5 $\mathrm{mm}$ in diameter), a Pt-wire electrode, and a saturated calomel electrode (SCE) were used as a working electrode, a counter electrode, and a reference electrode, respectively. All potentials are referenced with respect to the saturated calomel electrode (SCE) in this paper. The cyclic voltammetry $(\mathrm{CV})$ of the catalysts were measured in a potential range of $-0.25-1.2 \mathrm{~V}$ and at a scan rate of $50 \mathrm{mV} / \mathrm{s}$ at $25^{\circ} \mathrm{C}$ in $0.5 \mathrm{~mol} / \mathrm{L} \mathrm{H}_{2} \mathrm{SO}_{4}$ and $0.5 \mathrm{~mol} / \mathrm{L} \mathrm{H}_{2} \mathrm{SO}_{4}+0.5 \mathrm{~mol} / \mathrm{L}$ $\mathrm{CH}_{3} \mathrm{OH}$ solutions. $\mathrm{O}_{2}$ was removed from the solutions after saturating with high-purity $\mathrm{N}_{2}$ gas. The chronoamperometry curves were obtained by polarizing the electrode at $0.65 \mathrm{~V}$ for $1000 \mathrm{~s}$ in the $0.5 \mathrm{~mol} / \mathrm{L} \mathrm{H}_{2} \mathrm{SO}_{4}+0.5 \mathrm{~mol} / \mathrm{L} \mathrm{CH}_{3} \mathrm{OH}$ solution.

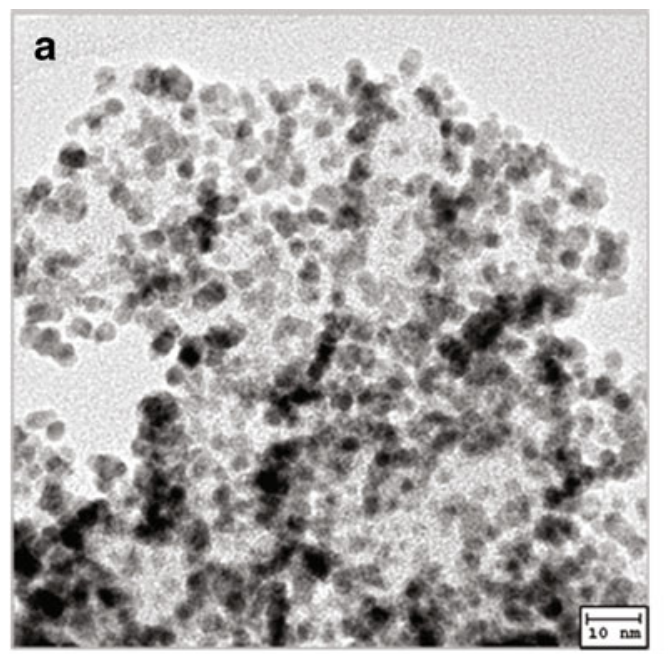

b
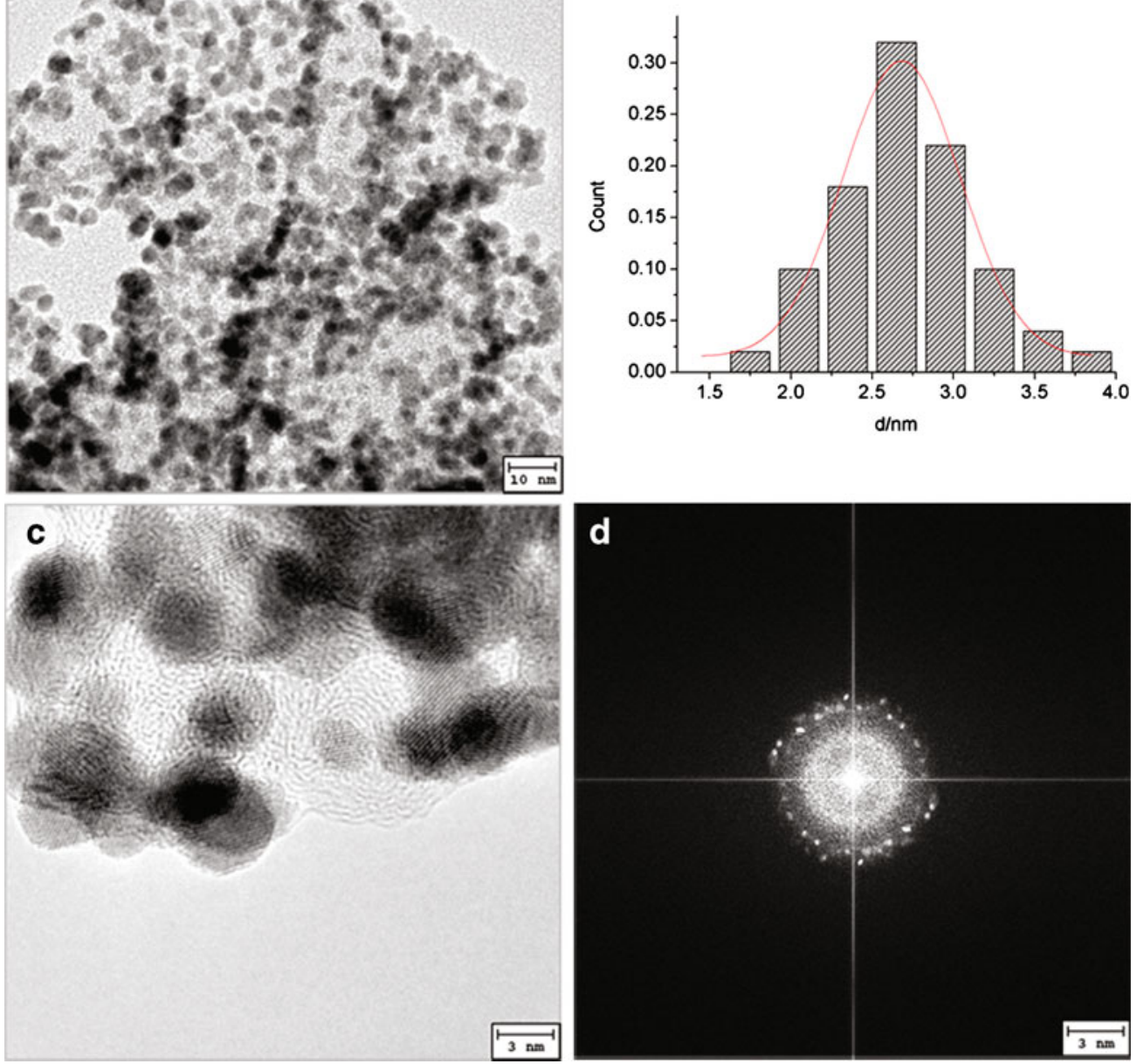

Figure 1. (a) and (c) HRTEM images; (b) histograms of particle size distribution; and (d) electron diffraction pattern of a region of Pt/CA catalyst. 


\section{Results and discussion}

Figure 1 shows the HRTEM images (a and c), the corresponding histograms of particle size distribution (b), and the corresponding electron diffraction pattern of a region of the Pt/CA catalyst (d). There is no obvious agglomeration in the sample. Figure 1(a) shows that the platinumcarbon aerogel catalyst consists of well-dispersed spherical platinum particles with an average diameter of $2.70 \mathrm{~nm}$. The histograms of the $\mathrm{Pt}$ particle size distribution of the Pt/CA catalyst (figure 1(b)) are obtained based on measurements of over 200 platinum particles.

XRD patterns for $\mathrm{Pt} / \mathrm{CA}$ and $\mathrm{Pt} / \mathrm{C}$ catalysts are shown in figure 2. The first weak diffraction peak of [002] reflection indicates the lower degree of graphitization of the reference for carbon aerogel. The characteristic diffraction peaks $\mathrm{Pt}$ [111] at $39^{\circ}, \mathrm{Pt}$ [200] at $45^{\circ}$, Pt [220] at $68^{\circ}$, and Pt [311] at $82^{\circ}$ for a face-centred cubic (fcc) structure are observed. The wide diffraction peaks of the catalysts indicate that the particle size of the platinum is very small, as shown in the HRTEM images.

The mean crystallite size of the catalysts was calculated via the Scherrer equation from the Pt [220] diffraction peak after background subtraction. The Scherrer equation is given by Hsin et al (2007)

$$
d=\frac{0 \cdot 9 \lambda_{k \alpha 1}}{B_{(2 \theta)} \cos \theta_{\max }},
$$

where $d$ is the average particle size $(\mathrm{nm}), \lambda_{k \alpha 1}$ is the wavelength of X-ray radiation $(0 \cdot 1542 \mathrm{~nm}), B_{(2 \theta)}$ is the width (in radians) of the diffraction peak at half height, and $\theta_{\max }$ is the angle of the diffraction peak [220].

The surface area of platinum (S) is obtained from the average diameter of the particles from HRTEM and XRD results by using the following equation (Guo et al 2005)

$$
S=\frac{6000}{d \rho},
$$

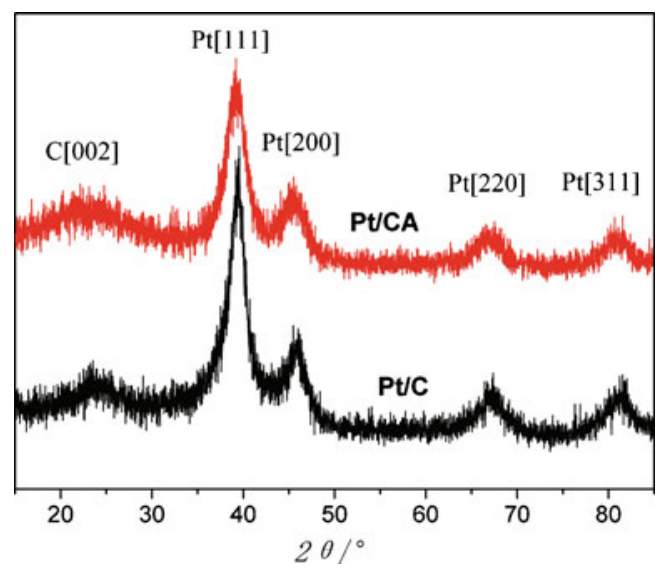

Figure 2. XRD patterns of $\mathrm{Pt} / \mathrm{CA}$ catalyst and $\mathrm{Pt} / \mathrm{C}$ catalyst (JM).
Table 1. Particle size, specific surface area, and EAS of $40 \%$ $\mathrm{Pt} / \mathrm{CA}$ catalyst and $40 \% \mathrm{Pt} / \mathrm{C}$ catalyst (JM).

\begin{tabular}{lllllll}
\hline \multirow{2}{*}{ Sample } & \multicolumn{2}{c}{$D(\mathrm{~nm})$} & & \multicolumn{2}{c}{$S\left(\mathrm{~m}^{2} / \mathrm{g}\right)$} & \multicolumn{1}{c}{$S_{\text {EAS }}$} \\
\cline { 2 - 3 } & $D_{\text {TEM }}$ & $D_{\text {XRD }}$ & & \multicolumn{1}{c}{$S_{\text {TEM }}$} & $S_{\text {XRD }}$ & $\left(\mathrm{m}^{2} / \mathrm{g}\right)$ \\
\hline Pt/CA $(40 \%)$ & 2.70 & 2.88 & & 103.83 & 97.35 & 50.04 \\
Pt/C (40\%) & 3.30 & 3.43 & & 84.96 & 81.74 & 43.65 \\
\hline
\end{tabular}

where $S$ is the surface area $\left(\mathrm{m}^{2} / \mathrm{g}\right), d$ is the average particle size $(\mathrm{nm})$, and $\rho$ is the density of platinum $\left(21.4 \mathrm{~g} / \mathrm{cm}^{3}\right)$.

The catalysts' mean crystallite size and surface area as obtained from HRTEM and XRD are listed in table 1. The average catalyst particle size calculated from the XRD peak widths agrees well with the HRTEM results.

To investigate the electrocatalytic activity of the $40 \mathrm{wt} . \%$ $\mathrm{Pt} / \mathrm{CA}$ catalyst, electrochemical measurements were carried out in $0.5 \mathrm{~mol} / \mathrm{L} \mathrm{H}_{2} \mathrm{SO}_{4}$ aqueous solution and $0.5 \mathrm{~mol} / \mathrm{L}$ $\mathrm{H}_{2} \mathrm{SO}_{4}+0.5 \mathrm{~mol} / \mathrm{L} \mathrm{CH}_{3} \mathrm{OH}$ aqueous solution at $25^{\circ} \mathrm{C}$. The cyclic voltammetry curves of the $\mathrm{Pt} / \mathrm{CA}$ catalyst and $\mathrm{Pt} / \mathrm{C}$ catalyst (JM) in $0.5 \mathrm{~mol} / \mathrm{L} \mathrm{H}_{2} \mathrm{SO}_{4}$ aqueous solution are given in figure 3 . The different hydrogen oxidation peaks are due to the presence of different $\mathrm{Pt}$ facets in the potential region $-0.25 \mathrm{~V}-0.05 \mathrm{~V}$. The well-defined Pt facets for the hydrogen oxidation peaks observed on the $\mathrm{Pt} / \mathrm{CA}$ catalyst are similar to those on the commercial Pt/C catalyst (JM) because of the similar graphitic nature of the carbon aerogel and the carbon in the $\mathrm{Pt} / \mathrm{C}$ catalyst. Pt/CA shows higher current density, indicating that the Pt/CA catalyst has higher electrochemical active area.

The electrochemical active surface (EAS) is calculated from the hydrogen desorption peak area $\left(Q_{\mathrm{H}}\right)$ on the cyclic voltammetry curves according to the following equation (Pozio et al 2002):

$$
\mathrm{S}_{\mathrm{EAS}}=\frac{Q_{H}}{0 \cdot 21[P t] V_{\mathrm{scan}}},
$$

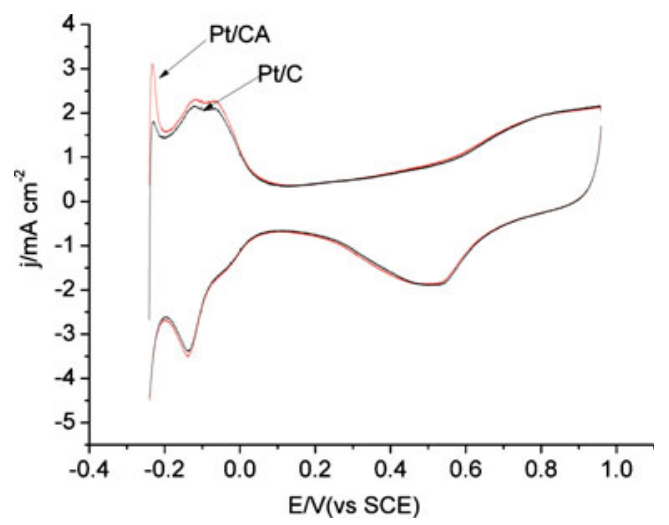

Figure 3. Cyclic voltammetry curves of $\mathrm{Pt} / \mathrm{CA}$ catalyst and $\mathrm{Pt} / \mathrm{C}$ catalyst (JM) in $0.5 \mathrm{~mol} / \mathrm{L} \mathrm{H}_{2} \mathrm{SO}_{4}$ solution. 
where the value of $0.21\left(\mathrm{mC} / \mathrm{cm}^{2}\right)$ represents the charge required to oxidize a monolayer of hydrogen, $[\mathrm{Pt}]$ is the platinum loading in the working electrode, and $V_{\text {scan }}$ is the scan rate. The EAS data of the Pt/CA catalyst and commercial $\mathrm{Pt} / \mathrm{C}$ catalyst are given in table 1 .

The cyclic voltammetry curves of the $\mathrm{Pt} / \mathrm{CA}, \mathrm{Pt} / \mathrm{C}$ and the pure Pt electrode in $0.5 \mathrm{~mol} / \mathrm{L} \mathrm{H}_{2} \mathrm{SO}_{4}+0.5 \mathrm{~mol} / \mathrm{L} \mathrm{CH}_{3} \mathrm{OH}$ aqueous solution are presented in figure 4 . It can be seen from figure 4 that one peak in the forward scan and one peak in the reverse scan also developed for $\mathrm{Pt} / \mathrm{CA}$ and $\mathrm{Pt} / \mathrm{C}$, showing similar voltammetric characteristics to the pure Pt electrode. However, the methanol oxidation current density increases significantly for $\mathrm{Pt} / \mathrm{CA}$ and $\mathrm{Pt} / \mathrm{C}$ compared to the pure $\mathrm{Pt}$ electrode. An obvious negative shift of the peak potential can be observed at $\mathrm{Pt} / \mathrm{CA}$ and $\mathrm{Pt} / \mathrm{C}$ compared to the pure Pt electrode. This shows that the electrocatalytic effect of methanol is due to Pt nanoparticles. The forward anodic peak between $0.50 \mathrm{~V}$ and $0.85 \mathrm{~V}$ is due to the oxidation of methanol. In the backward scan, the oxidation peak between $0.20 \mathrm{~V}$ and $0.50 \mathrm{~V}$ is due to the oxidation of $\mathrm{CO}$ or $\mathrm{CO}$-like species that are generated via the incomplete oxidation of methanol in the forward scan. Based on previous publication, the mechanism of methanol oxidation in acid solution can be summarized in the following reactions (Manoharan and Goodenough 1992; Jusys and Behm 2001; Liu et al 2010):

$$
\begin{aligned}
& \mathrm{CH}_{3} \mathrm{OH}_{\mathrm{ads}}+\mathrm{Pt} \rightarrow \mathrm{PtCO}_{\mathrm{ads}}+4 \mathrm{H}^{+}+4 e^{-}, \\
& \mathrm{H}_{2} \mathrm{O}+\mathrm{Pt} \rightarrow \mathrm{PtOH}_{\mathrm{ads}}+\mathrm{H}^{+}+e^{-}, \\
& \mathrm{PtOH}_{\mathrm{ads}}+\mathrm{PtCO}_{\mathrm{ads}} \rightarrow \mathrm{Pt}+\mathrm{Pt}+\mathrm{CO}_{2}+\mathrm{H}^{+}+e^{-} .
\end{aligned}
$$

Although the onset potentials for methanol oxidation on the $\mathrm{Pt} / \mathrm{CA}$ catalyst and $\mathrm{Pt} / \mathrm{C}$ catalyst $(\mathrm{JM})$ are almost the same, the peak current density for methanol oxidation of the $\mathrm{Pt} / \mathrm{CA}$ catalyst is higher than that of the commercial $\mathrm{Pt} / \mathrm{C}$ catalyst (JM). It should be noted that the peak potential for

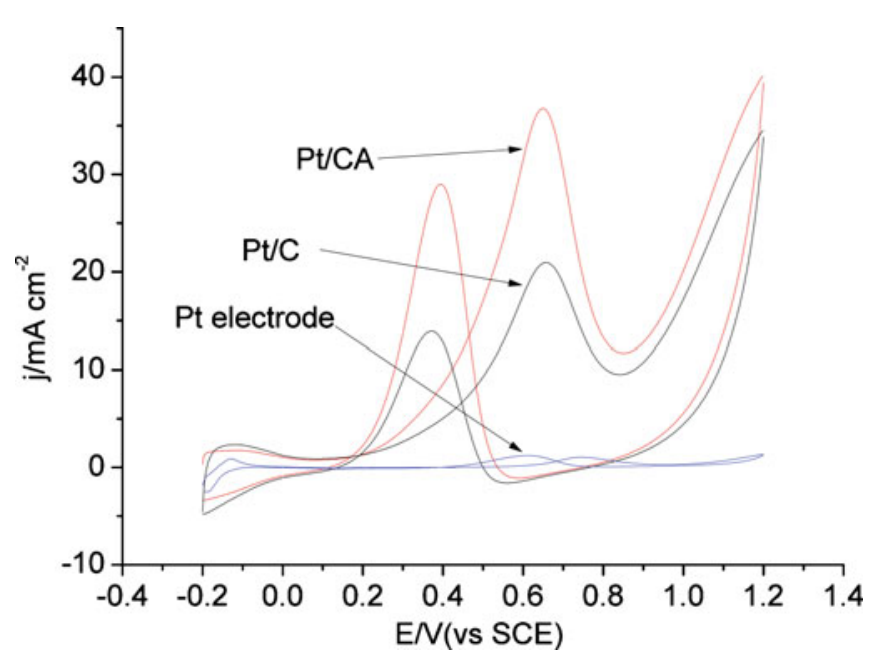

Figure 4. Cyclic voltammetry curves of $\mathrm{Pt} / \mathrm{CA}$ catalyst, $\mathrm{Pt} / \mathrm{C}$ catalyst $(\mathrm{JM})$ and the pure Pt electrode in $0.5 \mathrm{~mol} / \mathrm{L} \mathrm{H}_{2} \mathrm{SO}_{4}+0.5 \mathrm{~mol} / \mathrm{L}$ $\mathrm{CH}_{3} \mathrm{OH}$ solution.

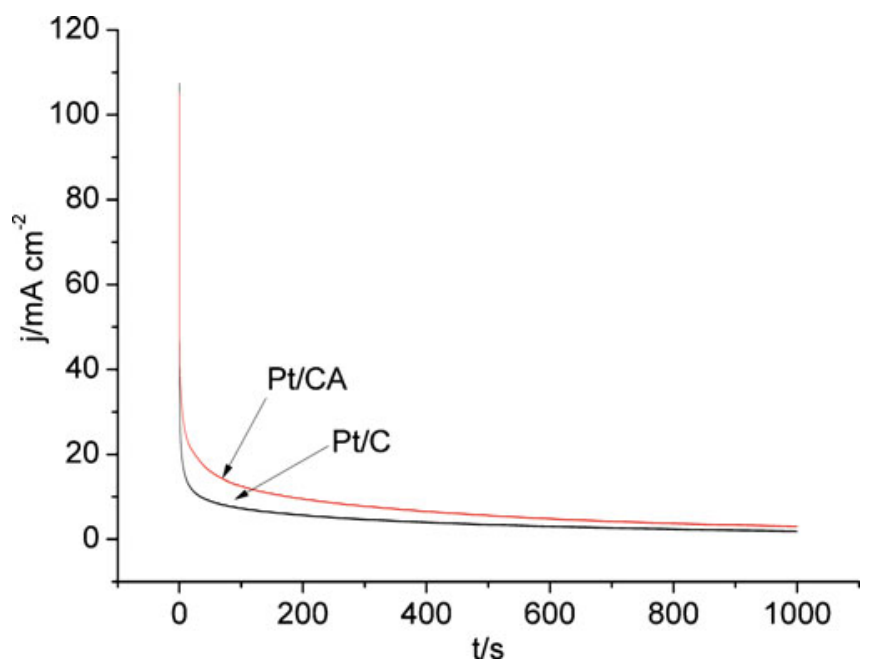

Figure 5. Chronoamperometry curves of $\mathrm{Pt} / \mathrm{CA}$ catalyst and $\mathrm{Pt} / \mathrm{C}$ catalyst (JM) in $0.5 \mathrm{~mol} / \mathrm{L} \mathrm{H}_{2} \mathrm{SO}_{4}+0.5 \mathrm{~mol} / \mathrm{L} \mathrm{CH}_{3} \mathrm{OH}$ solution.

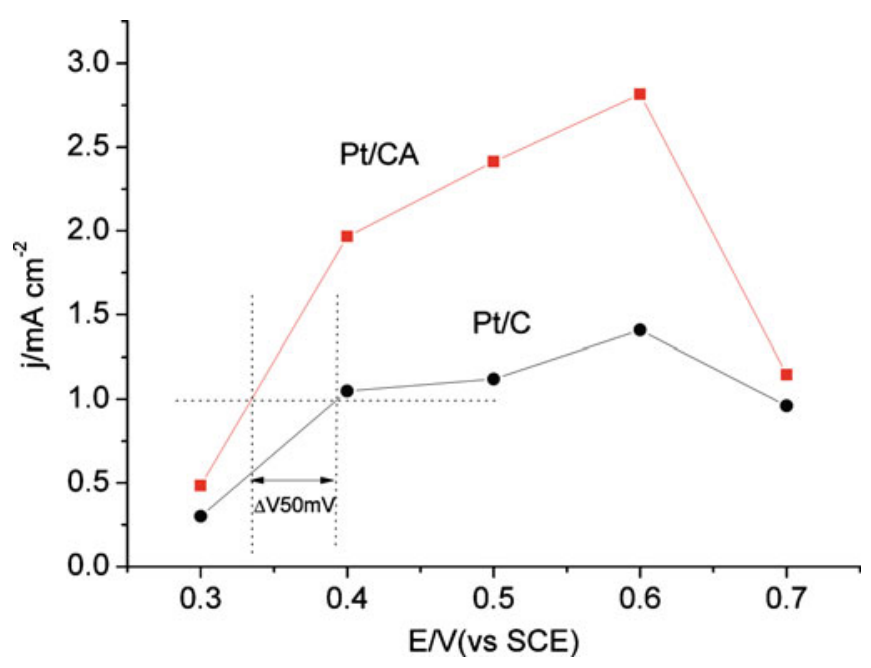

Figure 6. Potential-dependent steady-state current density of methanol oxidation on Pt/CA catalyst and Pt/C catalyst (JM).

methanol oxidation of the Pt/CA catalyst shifted $10 \mathrm{mV}$ in the negative direction relative to the commercial $\mathrm{Pt} / \mathrm{C}$ catalyst (JM). Both results indicate that using carbon aerogel as catalyst support can accelerate the oxidation of methanol due to the high surface area, the active mesoporous structure, and the graphitized structure.

Chronoamperometry measurements were made to provide further information on the electrochemical activity and stability of the Pt/CA catalyst for methanol oxidation. Figure 5 shows the current density vs time curves of the Pt/CA catalyst and $\mathrm{Pt} / \mathrm{C}$ catalyst $(\mathrm{JM})$ at a steady potential of $0.65 \mathrm{~V}$ for 1000 s. Similar to the CV results, the Pt/CA catalyst gives a higher limiting current density than the commercial catalyst. This also indicates that the Pt/CA catalyst has higher electrocatalytic activity and stability for methanol oxidation than those of the Pt/C catalyst (JM) at the same Pt loading (40\%). 
The enhanced electrochemical properties of the Pt/CA catalyst are due to the formation of smaller Pt nanoparticles and the excellent characteristics of the carbon aerogel.

The steady-state current density obtained from chronoamperometry measurements (recorded for various potentials, $0.3 \mathrm{~V}$ to $0.7 \mathrm{~V}$ ) corresponding to methanol oxidation is plotted against each respective potential in figure 6 in order to compare current density (Mahima et al 2008; Subhramannia et al 2008). The current density on Pt/CA form $0.3 \mathrm{~V}$ to $0.7 \mathrm{~V}$ is higher than that on $\mathrm{Pt} / \mathrm{C}$. Pt/CA and $\mathrm{Pt} / \mathrm{C}$ electrodes show maximum activity at a potential of $0.6 \mathrm{~V}$. From the potentialdependent current density curve, it is obvious that the potential on Pt/CA is shifted negatively by $50 \mathrm{mv}$ as compared to that of $\mathrm{Pt} / \mathrm{C}$ at the same current density of $1.0 \mathrm{~mA} / \mathrm{cm}^{2}$. Hence, the Pt/CA catalyst exhibits higher catalytic activity for the oxidation of methanol than $\mathrm{Pt} / \mathrm{C}$ catalyst.

All the electrochemical test results show that the platinum/carbon aerogel is a good catalyst for methanol oxidation and carbon aerogel is a good catalyst support for fuel cells.

\section{Conclusions}

A high-loading and highly dispersed $40 \mathrm{wt} \%$ platinum/carbon aerogel catalyst has been synthesized by the microwave-heated polyol method. The morphological properties of the platinum/carbon aerogel catalyst are evaluated by HRTEM, and it is found that the Pt particles have been well dispersed on the carbon aerogel with a mean size of $2.70 \mathrm{~nm}$. XRD analyses show the formation of $\mathrm{Pt}$ in the fcc phase. The average size of the platinum nanoparticles calculated from the XRD data agree well with the HRTEM results. The cyclic voltammetry curves in $0.5 \mathrm{~mol} / \mathrm{L}$ $\mathrm{H}_{2} \mathrm{SO}_{4}$ aqueous solution show that the $\mathrm{Pt} / \mathrm{CA}$ catalyst has a higher electrocatalytic surface area than that of a commercial Pt/C catalyst (JM) under the same Pt loading. The results from cyclic voltammetry and chronoamperometry measurements indicate that the Pt/CA catalyst shows higher electrochemical catalytic activity and electrochemical stability for methanol oxidation compared with the commercial catalyst. Based on all the results, we conclude that the Pt/CA catalyst has considerable potential to be an electrocatalyst for direct methanol fuel cells.

\section{Acknowledgements}

The authors gratefully acknowledge the financial support from the National Science Foundation of China (No. 20876013 and Key Program No. 20636060) and International S\&T Cooperation Program of China (No. 2009DFA63120).

\section{References}

Bai Y, Wu D, Wu F and Yi B L 2006 Mater. Lett. 602236

Chen W X, Lee J Y and Liu Z L 2002 Chem. Commun. 212588

Chen W X, Lee J Y and Liu Z L 2004 Mater. Lett. 583166

Guo J W, Zhao T S, Prabhuram J and Wong C W 2005 Electrochim. Acta $\mathbf{5 0} 1973$

Hsin Y L, Hwang K C and Yeh C T 2007 J. Am. Chem. Soc. 129 9999

Jusys Z and Behm R J 2001 J. Phys. Chem. B 10510874

Liang C H, Sha G Y and Guo S C 2000 J. Non-Cryst. Solids 271167

Liu Z L, Lee J Y, Chen W X, Han M and Gan L M 2004 Langmuir 20181

Liu H J, Wang X M, Cui W J, Dou Y Q, Zhao D Y and Xia Y Y 2010 J. Mater. Chem. 204223

Mahima S, Kannan R, Komath I, Aslam M and Pillai V K 2008 Chem. Mater. 20601

Maldonado-Hodar F J, Ferro-Garcia M A, Rivera-Utrilla J and Moreno-Castilla C 1999 Carbon 371199

Ma L, Zhang H M, Liang Y M, Xu D Y, Ye W, Zhang J L and Yi B L 2007 Catal. Commun. 8921

Manoharan R and Goodenough J B 1992 J. Mater. Chem. 2875

Pekala R W 1989 USA Patent 4873218

Pozio A, Francesco M D, Cemmi A, Cardellini F and Giorgi L 2002 J. Power Sources $\mathbf{1 0 5} 13$

Saliger R, Fischer U, Herta C and Fricke J 1998 J. Non-Cryst. Solids 22581

Subhramannia M, Ramaiyan K and Pillai V K 2008 Langmuir 24 3576

Tompsett G A, Conner W C and Yngvesson K S 2006 Chem. Phys. Chem. 7296

Wasmus S and Kuver J 1999 Electroanal. Chem. 46114

Wu D C, Fu R W, Zhang S, Dresselhaus M S and Dresselhaus G 2004 Carbon 422033

Zhu J F and Zhu Y J 2006 J. Phys. Chem. B 1108593 